\title{
Regulation of Alveolar Macrophage Transforming Growth Factor- $\beta$ Secretion by Corticosteroids in Bleomycin-induced Pulmonary Inflammation in the Rat
}

\author{
Nasreen Khalil, ** Carol Whitman, ${ }^{*}$ Li Zuo, ${ }^{*}$ David Danielpour, ${ }^{*}$ and Arnold Greenberg* \\ ${ }^{*}$ Department of Medicine, Section of Respiratory Diseases, ${ }^{\ddagger}$ Manitoba Institute of Cell Biology, University of Manitoba, Winnipeg, \\ Manitoba R3E OV9, Canada; and ${ }^{\S}$ Laboratory of Chemoprevention, National Institutes of Health, Bethesda, Maryland 20892
}

\begin{abstract}
In a model of pulmonary inflammation and fibrosis induced by the antineoplastic antibiotic, bleomycin, we previously demonstrated that TGF- $\beta$ was markedly elevated within $7 \mathrm{~d}$ of bleomycin administration. At the time of maximal TGF- $\beta$ production, TGF- $\beta_{1}$ was localized by immunohistochemistry to be present almost exclusively in alveolar macrophages. In this study, we have demonstrated that alveolar macrophages stimulated by bleomycin-induced injury secrete large quantities of biologically active TGF- $\beta_{1}$ when explanted into tissue culture. However, alveolar macrophages from normal saline-treated rats secrete small quantities of biologically inactive TGF- $\beta$. In contrast, splenic macrophages secrete large quantities of inactive TGF- $\beta$ and are unaffected by the intratracheal bleomycin treatment. High doses of the corticosteroid methylprednisolone given intramuscularly before and concomitantly with bleomycin administration prevented the influx of alveolar macrophages into the lungs, diminishing both the number of macrophages present in the alveoli and the total lung content of TGF- $\beta$. However, the rate of secretion of TGF- $\beta$ by alveolar macrophages recovered from the alveoli was unchanged after corticosteroid treatment. When activated alveolar macrophages were cultured in the presence of several concentrations of dexamethasone that completely suppressed IL-1 secretion, little effect on TGF$\beta$ secretion was observed.

The findings in this study demonstrate that during bleomycin-induced injury, alveolar macrophages not only secrete large quantities of active TGF- $\beta_{1}$, but are a predominant source of the enhanced TGF- $\beta$ response seen in this model. Furthermore, the alveolar macrophage secretion of TGF- $\beta$ is not inhibited by the presence of high concentrations of corticosteroids. (J. Clin. Invest. 1993. 92:1812-1818.) Key words: pulmonary fibrosis • interleukin-1 - transforming growth factor- $\beta_{1} \cdot$ transforming growth factor- $\beta_{2} \bullet$ transforming growth factor- $\beta_{3}$
\end{abstract}

\section{Introduction}

Interstitial pulmonary fibrosis occurs after a variety of lung injuries, (1) but the pathogenesis is unknown. Based on observation of pulmonary fibrosis in humans (2) and animal models of pulmonary fibrosis (3), it has been observed that enhanced

Address correspondence to Nasreen Khalil, M.D., Manitoba Institute of Cell Biology, 100 Olivia Street, Winnipeg, Mannitoba R3E 0V9, Canada.

Received for publication 18 September 1992 and in revised form 13 May 1993.

J. Clin. Invest.

(C) The American Society for Clinical Investigation, Inc.

0021-9738/93/10/1812/07 \$2.00

Volume 92, October 1993, 1812-1818 connective tissue synthesis is almost always preceded by an increase in the influx of activated inflammatory cells. Of these inflammatory cells, the alveolar macrophage is the most prominent cell in the alveolar space (4). In the steady state, alveolar macrophages comprise $>95 \%$ of the total alveolar cell population (4) and have been described to have numerous functions $(5,6)$. For example, the best recognized role for alveolar macrophages in the lung is to function as a nonspecific defense against inhaled foreign substances (7) and microorganisms (8). However, sufficient evidence now exists to suggest that alveolar macrophages may also have a role in pulmonary inflammation and fibrosis $(7,8)$. Not only do alveolar macrophages increase in number during pulmonary injury (3), but alveolar macrophages have been shown to produce a number of leukocyte and fibroblast regulating cytokines such as IL-1 (9), PDGF (10), TNF- $\alpha$ (11), TGF- $\beta$ (12), and proteins such as fibronectin (13).

Of the cytokines produced by alveolar macrophages, TGF$\beta$ is one of the most potent regulators of inflammation and connective tissue synthesis in vitro (14) and in vivo (15). TGF- $\beta_{1}$ is a $25-\mathrm{kD}$ homodimer that is constitutively transcribed by resting monocytes (16), and upon activation, monocytes (16) and macrophages have been shown to produce and secrete increased amounts of TGF- $\beta$ (17). Furthermore, TGF$\beta$ is produced by wound fibroblasts (18) and is a potent chemoattractant for fibroblasts (19) and induces them to synthesize collagen (20) and other proteins of the extracellular matrix (reviewed elsewhere) (21). The in vivo inflammatory and fibrogenic effects of TGF- $\beta$ are confirmed by observations that when TGF- $\beta$ is injected subcutaneously (15) or applied to incisions (22), there is an increase in infiltration of inflammatory cells and fibroblasts, as well as enhanced connective tissue synthesis.

We had previously shown in an animal model of pulmonary inflammation and fibrosis induced by the antineoplastic antibiotic bleomycin, that $7 \mathrm{~d}$ after intratracheal bleomycin administration, total lung TGF- $\beta$ increased 30 -fold above untreated control animals (12). Peak TGF- $\beta$ production preceded maximal collagen synthesis that occured later. Using immunohistochemistry and antibodies to a synthetic peptide of TGF- $\beta_{1}$, we localized the distribution of TGF- $\beta_{1}$ to alveolar macrophages at the time of maximal total lung TGF- $\beta$ content and throughout the course of bleomycin injury. It was also observed that although there was significant interstitial infiltration with lymphocytes, plasma cells, and macrophages, these cells did not express TGF- $\beta_{1}$. The distribution of matrix associated TGF- $\beta_{1}$ was seen later in the course of injury and coincided with maximal collagen synthesis (12). Furthermore, the matrix-associated TGF- $\beta_{1}$ was present in close apposition to the alveolar epithelium and not within areas of increased cellularity in the interstitium. Since only alveolar macrophages expressed TGF- $\beta_{1}$, our observations suggested that $(a)$ activated 
alveolar macrophages were the predominant source of the matrix-associated TGF- $\beta_{1}$; and $(b)$ once secreted by alveolar macrophages, TGF- $\beta_{1}$ then traversed the alveolar epithelium and associated with the extracellular matrix.

In the present study, we have demonstrated that alveolar macrophages isolated from bleomycin injured lungs secrete large quantities of biologically active TGF- $\beta_{1}$ isoform. Furthermore, this macrophage response is localized to the lungs, since splenic macrophages were not induced to secrete active TGF- $\beta$. In addition, macrophage influx and TGF- $\beta_{1}$ accumulation in the lungs could be prevented by immunosuppressive doses of corticosteroids. Although treatment of rats with corticosteroids decreased the number of infiltrating macrophages after bleomycin, they had no effect on macrophage secretion of active TGF- $\beta_{1}$. Furthermore, TGF- $\beta$ secretion by explanted alveolar macrophages activated by bleomycin induced injury or by LPS was not suppressed at doses of corticosteroids that completely blocked IL-1 secretion.

\section{Methods}

Animals. Female Sprague-Dawley rats, which were free of respiratory disease and weighed between 250 and $300 \mathrm{~g}$, were obtained from the University of Manitoba vivarium. In each experiment, all rats were matched for age and weight.

Reagents. Bleomycin (Blenoxane) was a gift from Bristol Laboratories (Bristol-Meyers Co., Evansville, IN). Neutralizing turkey and rabbit antibodies to TGF- $\beta_{1}$ and TGF- $\beta_{2}$, respectively, were from David Danielpour (National Institutes of Health, Bethesda, MD). (23) Porcine TGF- $\beta_{1}$ was obtained from R \& D Systems, Inc. (Minneapolis, MN). Mouse monoclonal anti-TGF- $\beta_{1,2,3}$ IgG was obtained from Genzyme Corp. (Cambridge, MA).

Bleomycin administration. Rats were anesthestized by an intraperitoneal injection of $40 \mathrm{mg} / \mathrm{kg}$ of Nembutal (Abbott Laboratories, Toronto, Ontario). Tracheostomy was performed and sterile normal saline containing $1 \mathrm{U}$ of bleomycin sulfate (Blenoxane; Bristol-Myers Co.) in $500 \mu$ l of normal saline was instilled into the lungs using a 25-gauge needle inserted between the cartilaginous rings of the trachea. Control animals received $500 \mu \mathrm{l}$ of normal saline only. The tracheal site of surgery was sutured and the rats were allowed to recover until the time of death. In some experiments, $30 \mathrm{mg} / \mathrm{kg}$ of methylprednisolone (Upjohn Co., Don Mills, Ontario, Canada) was given intramuscularly for $2 \mathrm{~d}$ before intratracheal administration of bleomycin. Thereafter, the rats received daily intramuscular injections of $15 \mathrm{mg} / \mathrm{kg}$ of methylprednisolone until the day of sacrifice. $7 \mathrm{~d}$ after bleomycin treatment, the rats were killed by receiving a lethal dose of Nembutal. A thoracotomy was done to expose the heart and lungs. Systemic blood was removed from the lungs by severing the inferior vena cava and flushing the lungs through the right ventricle with PBS until the lungs appeared pearly white. The lungs were then lavaged to obtain cells for differential counting or for overnight culture of alveolar macrophages. For some experiments, the lungs were frozen in liquid nitrogen and stored in $-70^{\circ} \mathrm{C}$ until ready for TGF- $\beta$ extraction.

Macrophage cultures. Alveolar macrophages were obtained by cannulating the trachea, instilling and retrieving 5-ml aliquots of sterile normal saline to an accumulative volume of $\sim 50 \mathrm{ml}$. The entire lavage volume was centrifuged and the cell pellet suspended in $\alpha$-MEM (Gibco Laboratories, Grand Island, NY) with $10 \%$ FCS (Gibco Laboratories).

The cell count was adjusted to $1 \times 10^{6} / \mathrm{ml}$ and aliquoted as 2 $\times 10^{6} / 6 \mathrm{~mm}$ tissue culture plate (Nunclon, Roskile, Denmark). Viability, determined by exclusion of typan blue or appearance by polarized microscopy (24) was $>95 \%$. One plate treated in the identical manner was used for esterase staining. Esterase staining (25) was used to determine the percentage of macrophages present at the time of collection of conditioned media.
Single cell suspensions were recovered from spleens by disaggregating them on a wire mesh and seiving through a $1-\mathrm{mm}$ gauge wire mesh to remove large pieces of tissue. The cell suspension was layered over Lymphocyte-M (Cedarlane Laboratories, Hornby, Ontario) and centrifuged at 1,200 rpm for $30 \mathrm{~min}$. The mononuclear cell band was harvested, washed, and resuspended in $\alpha$-MEM with $10 \%$ FCS at a concentration of $1 \times 10^{6}$ cells $/ \mathrm{ml}$ and aliquoted as $2 \times 10^{6}$ cells $/ 6-\mathrm{mm}$ culture plates. Viability was tested as above. Macrophages were identified by esterase staining as above.

Differential counts. Cells obtained by bronchoalveolar lavage as previously described were suspended at a concentration of $1 \times 10^{6}$ cells $/ \mathrm{ml}$ were used in cytospin preparations. The cells were stained using the Diff-Quick (Baxter Healthcare Corp., Miami, FL) fixative and nuclear/cytoplasmic stains. Five fields at high power were used to enumerate and identify cells as macrophages, neutrophils, lymphocytes, and others. Cells were classified as "others" if they did not conform to the morphology of macrophages, neutrophils, or lymphocytes.

In vitro effects of corticosteroids. Alveolar macrophages obtained after intratracheal bleomycin were cultured in the presence of dexamethasone sodium phosphate, (Sabex, Montreal, Quebec, Canada) for $24 \mathrm{~h}$, and the conditioned media was collected as described below. Alveolar macrophages obtained from untreated rats were stimulated by LPS (Escherichia coli serotype 0111:B41; Sigma Immunochemicals, St. Louis, MO), and cultured in the presence of varying concentrations of dexamethasone for $24 \mathrm{~h}$. The conditioned media was collected as described below. Parallel aliquots of this conditioned media were used to determine the IL- 1 and TGF- $\beta$ content.

Collection of conditioned media (CM). After aliquoting $2 \times 10^{6}$ cells/well the macrophages were allowed to adhere for $2 \mathrm{~h}$. The plates were then washed with $\alpha$-MEM and cultured in serum-free media containing $20 \mathrm{mM}$ Hepes, $4 \mathrm{mg} / 100 \mathrm{ml}$, Gentamicin (Roussel, Montreal, Quebec, Canada), $100 \mu \mathrm{l} / 100 \mathrm{ml}$, Fungizone (Gibco Laboratories), and $0.2 \%$ clotted bovine calf plasma (National Biological Laboratory Ltd., Dugald, Manitoba, Canada). After $24 \mathrm{~h}$ of incubation at $37^{\circ} \mathrm{C}$, $95 \% \mathrm{CO}_{2}$ the media was collected in the presence of $0.5 \mu \mathrm{g} / \mathrm{ml}$ leupeptin, $5 \mu \mathrm{g} / \mathrm{ml}$ aprotinin, and pepstatin $(1 \mu \mathrm{g} / \mathrm{ml}$; (all three from United States Biochemical Corp., Cleveland, $\mathrm{OH}$ ), and aliquoted and frozen at $-80^{\circ} \mathrm{C}$ until ready for TGF- $\beta$ quantitation or isoform characterization. A representative well of alveolar macrophages cultured, maintained, and washed in an identical manner as above was used for calculation of esterase positive cells representing the percentage of macrophages of the adherent cells present in culture.

$T G F-\beta$ extraction from whole lungs. $4 \mathrm{ml}$ of an acid-ethanol solution (95\% ethanol, $0.2 \mathrm{M} \mathrm{HCl}$ ) containing $1 \mu \mathrm{g} / \mathrm{ml}$ each of PMSF (Sigma Immunochemicals) and pepstatin was added to previously frozen lungs as described (12). The lungs were homogenized using a tissue homogenizer (Polytron; Brinkmann Instruments Co., Westbury, NY). The homogenate was stirred overnight at $4^{\circ} \mathrm{C}$ and centrifuged at $10,000 \mathrm{~g}$ for $10 \mathrm{~min}$. The supernatant was diluted with two parts distilled water and was then lyophilized. It was then resuspended in $2 \mathrm{ml}$ of $4 \mathrm{mM} \mathrm{HCl}$ with $0.1 \% \mathrm{BSA}$ per lung, centrifuged to remove insoluble particles, and then stored at $-80^{\circ} \mathrm{C}$ until assayed. Samples were neutralized with $2-3 \mu \mathrm{l}$ of $5 \mathrm{~N} \mathrm{NaOH}$ and $1 \mathrm{M}$ Hepes before use, and any precipitate was removed by a 5 -min centrifugation at $10,000 \mathrm{rpm}$ on a microfuge (Beckman Instruments, Inc., Palo Alto, CA).

$C C L-64$ mink lung epithelial growth inhibition assay for TGF- $\beta$. CCL-64 mink lung epithelial cells were maintained in $\alpha$-MEM with $10 \%$ FBS. Subconfluent cells were used in the TGF- $\beta$ growth inhibition assay as described by Danielpour et al $(12,26)$. Cells were trypsinized and washed with $\alpha$-MEM in $0.2 \%$ bovine calf plasma and resuspended in $\alpha$-MEM, $0.2 \%$ clotted bovine plasma, and $10 \mathrm{mM}$ Hepes at $\mathrm{pH} 7.4$, as well as penicillin $(25 \mu \mathrm{g} / \mathrm{ml})$ and streptomycin $(25 \mu \mathrm{g} / \mathrm{ml})$, and cultured as $5 \times 10^{4}$ cells $/ 0.5 \mathrm{ml}$ in 24-well Costar dishes (Flow Laboratories, Inc., Missisauga, Ontario, Canada). Neutral conditioned media or conditioned media that was acidified and subsequently neutralized or aliquots of neutralized acid-extracted lung preparations in the presence or absence of anti-TGF- $\beta$ antibodies were added $3 \mathrm{~h}$ later. After $22 \mathrm{~h}$, the cells were pulsed with $0.25 \mu \mathrm{Ci}(5 \mathrm{Ci} / \mathrm{mg})$ of $5-\left[{ }^{125} \mathrm{I}\right]$ iodo 
Table I. Alveolar and Splenic Macrophage Secretion of TGF- $\beta$ after Intratracheal Bleomycin or Normal Saline Administration

\begin{tabular}{|c|c|c|c|c|c|}
\hline \multirow[b]{2}{*}{$\begin{array}{l}\text { Source of conditioned } \\
\text { media (CM) }\end{array}$} & \multirow[b]{2}{*}{$\begin{array}{c}\text { Intratracheal } \\
\text { treatment }\end{array}$} & \multicolumn{2}{|c|}{ TGF $-\beta\left(\mathrm{pg} / 10^{6} \text { macrophages per } 24 \mathrm{~h} \pm \mathrm{SE}\right)^{*}$} & \multirow[b]{2}{*}{$\begin{array}{l}\text { Percent active } \\
\text { TGF- } \beta\end{array}$} & \multirow[b]{2}{*}{$\begin{array}{l}P \text { comparing TGF- } \beta \text { conten } \\
\text { of neutral CM to } \\
\text { acidified CM }\end{array}$} \\
\hline & & $\begin{array}{l}\text { Neutral conditioned } \\
\text { media }\end{array}$ & $\begin{array}{l}\text { Acidified } \\
\text { conditioned } \\
\text { media }\end{array}$ & & \\
\hline Alveolar macrophages & Normal saline & $26.8 \pm 3.8$ & $123.5 \pm 15.4$ & 21.7 & $\leq 0.02$ \\
\hline Alveolar macrophages & Bleomycin & $424.3 \pm 50.8^{\ddagger}$ & $538.8 \pm 49.3^{\S}$ & 78.8 & NS \\
\hline Splenic macrophages & Normal saline & 0.0 & $199.2 \pm 43.2$ & 0 & $<0.001$ \\
\hline Splenic macrophages & Bleomycin & 0.0 & $148.8 \pm 31.2^{\prime \prime}$ & 0 & $<0.001$ \\
\hline
\end{tabular}

${ }^{*}$ Results are means of values obtained from CM of overnight cultures of alveolar macrophages from four to six rats. ${ }^{\ddagger} P=0.006 .(P$ obtained by comparing the TGF- $\beta$ content in neutral CM from alveolar macrophages after intratracheal bleomycin administration compared to intratracheal normal saline administration). ${ }^{\S} P \leq 0.01$. ( $P$ obtained by comparing the TGF- $\beta$ content in acidified CM from alveolar macrophages after intratracheal bleomycin administration compared to intratracheal normal saline administration). " $P$ value is not significant. ( $P$ obtained by comparing the TGF- $\beta$ content in acidified CM from splenic macrophages after intratracheal bleomycin administration compared to intratracheal normal saline administration).

2'-deoxyuridine (Amersham Corp., Arlington Heights, IL) for 2-3 h at $37^{\circ} \mathrm{C}$. Cells were then fixed with $1 \mathrm{ml}$ of methanol-acetic acid $(3: 1)$ ( vol/vol). After $1 \mathrm{~h}$ at room temperature, the wells were washed twice with $2 \mathrm{ml}$ of $80 \%$ methanol. The cells were lysed with $1 \mathrm{ml}$ of $1 \mathrm{~N}$ $\mathrm{NaOH}$ for $30 \mathrm{~min}$ at room temperature and the $5^{\prime}-\left[{ }^{125} \mathrm{I}\right]$ iodo- $2^{\prime}-$ deoxyuridine was counted in a gamma counter (LKB Instruments, Inc., Gaithersburg, MD). A standard curve of porcine TGF- $\beta$ was included in each assay and data were expressed as picograms or nanograms of TGF- $\beta_{1}$, as described $(12,26)$. For isoform characterization and confirmation of TGF- $\beta$ activity, the neutralizing turkey antibody to TGF- $\beta_{1}$ and rabbit antibody to TGF- $\beta_{2}$ (prepared by D. Danielpour) or mouse monoclonal antibody to TGF- $\beta_{1-3}$ (Genzyme Corp.) were added before the addition of the conditioned media.

Antisera prepared by Dr. Danielpour had previously been tested for their ability to neutralize native TGF- $\beta_{1}$ or TGF- $\beta_{2}$. These antisera blocked $100 \%$ of both the receptor binding and growth inhibitory activity of the peptides (23). On Western blot analyses, TGF- $\beta_{1}$ or TGF- $\beta_{2}$ reacted with complete specificity with no antibody crossreactivity (26). In the CCL-64 growth inhibition assay, 10 pM of TGF- $\beta_{1}$ and TGF- $\beta_{2}$ were blocked completely by a dilution of $1: 1,000$ of anti-TGF- $\beta_{1}$ and $1: 3,000$ of anti-TGF- $\beta_{2}$ antibodies, respectively (26). Anti-TGF- $\beta_{1,2}$ were used in parallel with their respective nonimmune sera in all assays. No effect could be attributed to the nonimmune sera.

Interleukin-1 bioassay. A sensitive bioassay for interleukin-1 developed by Gearing et al. (27) was used to quantitate the IL-1 in conditioned media obtained from alveolar macrophages. Briefly, NOB-1 cells (American Type Culture Collection, Rockville, MD) maintained in RPMI-1640 (Gibco Laboratories) containing 5\% fetal bovine serum (Gibco Laboratories) were seeded as $5 \times 10^{4}$ cells/well in a 96-well, flat-bottomed plates (Nunclon). IL-1 standards using human recombinant IL-1 beta ( $R$ \& D Systems, Inc.), were prepared at concentrations of $0,3,10,30,100,300$, and $1,000 \mathrm{pg} / \mathrm{ml}$. A $20-\mu 1$ aliquot of the standard or macrophage conditioned media was added to each well, and the volume was made up to $200 \mu \mathrm{l}$. The cells were incubated for 24 $\mathrm{h}\left(37^{\circ} \mathrm{C}\right.$ in $\left.5 \% \mathrm{CO}_{2}\right)$ centrifuged, and $100 \mu \mathrm{l}$ of the supernatant was transferred to wells containing $1 \times 10^{4}$ clone of cytotoxic T lymphocyte independent of IL-2 (CTLL) ${ }^{1}$ cells (American Type Culture Collection) in $100 \mu$ l of media and incubated for an additional 24 h. $4 \mathrm{~h}$ before harvest, the wells were pulsed with $0.5 \mu \mathrm{Ci}$ of $\left[{ }^{3} \mathrm{H}\right]$ thymidine then harvested, placed into a scintillation cocktail (Beta-Max; ICN, Irvine, CA), and counted in a beta scintillation counter (Beckman Instruments, Inc.). IL-1 concentration of the supernatant was determined by comparing the counts to those obtained from the IL-1 standard curve.

1. Abbreviations used in this paper: CM, conditioned media; CTLL, clone of cytotoxic T lymphocyte independent of IL-2; L-TGF- $\beta$, latent transforming growth factor- $\beta$; MTP-A, methylprednisolone-acetate.
Statistical analysis. Values were compared by using ANOVA with single or multiple pairwise comparisons when the variances were equal. However, when the variances were unequal, the data were analyzed using a nonparametric approach, as well as a logarithmic transformation of the data. The later two methods of analysis gave the same results.

\section{Results}

Alveolar macrophage secretion of $T G F-\beta$. In a previous study, we demonstrated that total lung TGF- $\beta$ was maximally elevated $7 \mathrm{~d}$ after intratracheal bleomycin when it was exclusively in alveolar macrophages by immunohistochemistry (12). For this reason, subsequent studies on alveolar macrophage secretion of TGF- $\beta$ were conducted $7 \mathrm{~d}$ after bleomycin instillation. To determine whether or not alveolar macrophages secrete TGF- $\beta_{1}$, alveolar macrophages obtained $7 \mathrm{~d}$ after bleomycin administration were maintained in serum-free conditions for $18-20 \mathrm{~h}$, and the conditioned medium collected. TGF- $\beta$ was quantitated both before and after activation by acidification. TGF- $\beta$ obtained from most normal cells, platelets and tissues is biologically inactive (28). Conditioned media obtained from alveolar macrophages after intratracheal normal saline treatment contained small quantities of TGF- $\beta$ ( Table I). However, after bleomycin treatment, secretion increased four- to fivefold, and $79 \%$ of the TGF- $\beta$ was in the active form (Table I). To examine if the enhanced secretion of active TGF- $\beta$ was localized to the lungs, we obtained conditioned media from overnight cultures of splenic macrophages from both normal saline and bleomycin treated rats. Although splenic macrophages secreted as much TGF- $\beta$ as normal alveolar macrophages it was all in the biologically inactive form (Table I) and was unaffected by the intratracheal bleomycin treatment ( Table I).

TGF- $\beta$ exists in three isoforms designated as TGF- $\beta_{1}$, TGF$\beta_{2}$, and TGF- $\beta_{3}(14)$. Neutralizing antibodies to TGF $-\beta_{1}$, TGF $-\beta_{2}$, and TGF- $\beta_{1-3}$ were used in the CCL-64 bioassay to quantitate the relative amounts of each isoform in the conditioned media from alveolar macrophage. In the presence of anti-TGF- $\beta_{1-3}$ (Genzyme Corp.) all TGF- $\beta$ activity was neutralized confirming the specificity of the CCL-64 bioassay in detecting the TGF- $\beta$ s. Furthermore, $50 \%$ of the total TGF- $\beta$ activity in the conditioned media from inactive alveolar macrophages was TGF- $\beta_{1}$, while TGF- $\beta_{2}$ and TGF- $\beta_{3}$ were present in 
Table II. Isoforms of the TGF- $\beta$ Secreted by Alveolar Macrophages after Normal Saline or Bleomycin Treatment

\begin{tabular}{|c|c|c|c|c|c|c|}
\hline \multirow[b]{2}{*}{$\begin{array}{l}\text { Intratracheal } \\
\text { treatment }\end{array}$} & \multicolumn{2}{|c|}{ TGF- $\beta_{1}$} & \multicolumn{2}{|c|}{ TGF- $\beta_{2}$} & \multicolumn{2}{|c|}{ TGF- $\beta_{3}$} \\
\hline & $\begin{array}{l}\mathrm{pg} / 10^{6} \text { macrophages } \\
\text { per } 24 \mathrm{~h} \pm \mathrm{SE}^{*}\end{array}$ & $\begin{array}{l}\text { Percent of total } \\
\text { TGF- } \beta \text { activity }\end{array}$ & $\begin{array}{l}\text { pg/ } / 10^{6} \text { macrophages } \\
\text { per } 24 \mathrm{~h} \pm \mathrm{SE}^{*}\end{array}$ & $\begin{array}{l}\text { Percent of total } \\
\text { TGF- } \beta \text { activity }\end{array}$ & $\begin{array}{l}\text { pg } / 10^{6} \text { macrophages } \\
\text { per } 24 \mathrm{~h} \pm \mathrm{SE}^{*}\end{array}$ & $\begin{array}{l}\text { Percent of total } \\
\text { TGF- } \beta \text { activity }\end{array}$ \\
\hline Normal saline & $35.9 \pm 2.4$ & $49.8 \pm 9.7$ & $32.2 \pm 8.5$ & $32.8 \pm 4.4$ & $30.1 \pm 12.8$ & $24.3 \pm 7, .5$ \\
\hline Bleomycin & $201.1 \pm 3.7$ & $77.1 \pm 1.1$ & $35.6 \pm 3.4$ & $13.5 \pm 0.9$ & $27.7 \pm 3.4$ & $9.5 \pm 1.2$ \\
\hline$P$ value ${ }^{\S}$ & 0.0007 & NS & NS & NS & NS & NS \\
\hline
\end{tabular}

* Results are means of values obtained from CM of overnight cultures of alveolar macrophages from four to six rats. ${ }^{\ddagger}$ Conditioned media was acidified and then neutralized to obtain total TGF- $\beta$ activity. Isoform characterization was done on conditioned media previously acidified to obtain total TGF- $\beta$ activity in the sample. ${ }^{\S} P$ comparing TGHF- $\beta$ content of CM from alveolar macrophages after intratracheal bleomycin administration compared to intratracheal normal saline administration. NS represents values that are not significantly different from each other.

approximately equal quantities. However, after bleomycin administration, activated alveolar macrophages increased the secretion of TGF- $\beta_{1}$ five- to sixfold while the quantities of TGF$\beta_{2}$ and TGF- $\beta_{3}$ remained unchanged (Table II).

Effects of corticosteroids on total lung TGF- $\beta$ content and alveolar macrophage secretion of TGF- $\beta$. We reasoned that if alveolar macrophages were the primary source of lung TGF- $\beta 7$ $\mathrm{d}$ after bleomycin administration, then inhibiting influx of macrophages into the lungs should abrogate the TGF- $\beta$ response. Immunosuppressive doses of corticosteroids have been shown to reduce wound macrophages, wound closure, and wound strength (29). Based on these findings, methylprednisolone was given to Sprague Dawley rats $2 \mathrm{~d}$ before intratracheal bleomycin and the immunosuppression was continued until the time of death $7 \mathrm{~d}$ later. Examination of the cellular content of bronchoalveolar lavage after saline treatment revealed that there were $3.5 \pm 0.8 \times 10^{6}$ alveolar macrophages present and represented $92 \%$ of the alveolar cell population. After bleomycin administration the absolute number of macrophages remained unchanged but the overall number of alveolar cells increased (Table III). When immunosuppressive doses of methylprednisolone were administered concomitantly with bleomycin, the total number of cells in the bronchoalveolar lavage were reduced by $\sim 13$-fold while alveolar macrophages were reduced by 38 -fold. In addition to the reduction in alveolar macrophages, there was a profound reduction in total lung content of TGF- $\beta$ compared to rats treated with bleomycin alone, as well as control rats not receiving bleomycin (Table IV). It was noted that the few alveolar macrophages remaining in rats treated with bleomycin and methylprednisolone continued to secrete active TGF- $\beta_{1}$ at the same rate as macrophages obtained from rats not treated with corticosteroids (Table IV). The failure of systemic corticosteroids on alveolar macrophage secretion of TGF- $\beta$ may have been caused by an inadequate concentration of corticosteroids in the alveolar compartment. However, when larger intramuscular doses of methylprednisolone were administered, it resulted in severe corticosteroid induced toxicity and death of all rats. To directly determine the effects of known concentrations of corticosteroids on alveolar macrophages, we examined the TGF- $\beta$ content of conditioned media from alveolar macrophages obtained from bleomycintreated rats cultured in vitro in the presence of increasing concentrations of dexamethasone. To confirm that the dexamethasone was sufficient to affect cytokine production by activated alveolar macrophages, conditioned medium was also examined for IL-1. Corticosteroids have been shown to inhibit IL-1 transcription and secretion by activated macrophages $(30)$ and monocytes (31). Alveolar macrophages activated by bleomycin-induced injury secreted enhanced quantities of IL-1 and the secretion of IL-1 was abrogated by as little as $0.1 \mathrm{mM}$ of dexamethasone (Fig. 1). However, the secretion of TGF- $\beta$ was not suppressed and was somewhat increased in the presence of dexamethasone (Fig. 1).

It was possible that once alveolar macrophages had been activated to secrete TGF- $\beta$ after bleomycin administration, they were insensitive to corticosteroid inhibition. We next obtained alveolar macrophages from untreated rats and after in vitro adherence for $2 \mathrm{~h}$, stimulated them with LPS in the pres-

Table III. Effects of Systemic Methylprednisolone-Acetate (MTP-A) on the Alveolar Leukocyte Population*‡

\begin{tabular}{|c|c|c|c|c|c|c|c|c|c|}
\hline \multirow[b]{2}{*}{ Treatment } & \multicolumn{2}{|c|}{ Macrophages } & \multicolumn{2}{|c|}{ Lymphocytes } & \multicolumn{2}{|c|}{ Neutrophils } & \multicolumn{2}{|c|}{ Others } & \multirow{2}{*}{$\begin{array}{l}\text { Total cells } \\
\left(\times 10^{6} \pm \mathrm{SE}\right)\end{array}$} \\
\hline & $\times 10^{6}$ & Percent of total & $\times 10^{6}$ & Percent of total & $\times 10^{6}$ & Percent of total & $\times 10^{6}$ & Percent of total & \\
\hline Normal saline & $3.5 \pm 0.8$ & $92 \pm 0.9$ & $0.3 \pm 0.1$ & $0.5 \pm 0.1$ & $0.02 \pm 0.1$ & $5.2 \pm 2.6$ & 0.01 & $0.03 \pm 0.01$ & $3.8 \pm 0.3$ \\
\hline Bleomycin $^{\S}$ & $3.8 \pm 0.5$ & $31 \pm 3.9$ & $4.3 \pm 0.5$ & $35.0 \pm 3.9$ & $1.9 \pm 0.2$ & $15.7 \pm 1.7$ & $2.3 \pm 0.4$ & $21 \pm 3.3$ & $12.6 \pm 12$ \\
\hline $\begin{array}{l}\text { Bleomycin }^{8} \\
\text { and MTP-A" }\end{array}$ & $0.01 \pm .03^{1}$ & $1 \pm 0.3$ & $0.8 \pm 0.4$ & $80.0 \pm 3.0$ & $0.1 \pm .02$ & $10 \pm 0.3$ & $.02 \pm .01$ & $2.0 \pm 0.8$ & $1.0 \pm 0.2$ \\
\hline
\end{tabular}

* Cell differential counts are an average of three to four animals. ${ }^{\ddagger}$ All changes in cell numbers were statistically significant $(P=0.0001-0.01)$ except for number of macrophages obtained after normal saline and bleomycin administration. However, the change in percent of macrophages of the total number of cells after bleomycin administration compared to normal saline administration was significant $(P=0.0001)$. ${ }^{8}$ Normal saline and bleomycin were administered intratracheally. The dose and schedule of administration is described in Methods. "MTP-A was given in intramuscularly according to the dose and schedule described in Methods. 'Reduction in the number of macrophages in animals treated with bleomycin concomitantly with MTP-A compared to bleomycin alone was 38-fold. 
Table IV. Effects of MTP-A on the Total Lung Content of TGF- $\beta$ and Alveolar Macrophage Secretion of TGF- $\beta$

\begin{tabular}{|c|c|c|}
\hline Treatment & $\begin{array}{c}\text { TGF- } \beta^{*} \\
\text { (ng) }\end{array}$ & $\begin{array}{c}\text { Total TGF- } \beta \text { secreted }{ }^{\ddagger} \\
\text { by alveolar macrophages } \\
\text { (pg/10 } / 10^{6} \text { cells per } 24 \mathrm{~h} \pm \mathrm{SE} \text { ) }\end{array}$ \\
\hline Normal saline & $5.0 \pm 1.2$ & $48.4 \pm 2.4$ \\
\hline Bleomycin ${ }^{8}$ & $141.7 \pm 7.8^{1}$ & $187.2 \pm 40.8^{\ddagger \ddagger}$ \\
\hline \multicolumn{3}{|l|}{ Bleomycin ${ }^{\S}$ and } \\
\hline MTP-A" & $1.8 \pm 0.2^{* *}$ & $178.8 \pm 84.0^{88}$ \\
\hline
\end{tabular}

* TGF- $\beta$ values are a mean of total lung TGF- $\beta$ in extracts from six rats. ${ }^{\ddagger}$ TGF- $\beta$ values are a mean of TGF- $\beta$ content in CM from alveolar macrophages obtained from four to six rats. ${ }^{8}$ Normal saline and bleomycin were administered intratracheally. The dose and schedule are described in Methods. "MTP-A was given intramuscularly according to the dose and schedule described in Methods. ' $P$ $=0.0001$ ( $P$ was obtained comparing total lung TGF- $\beta$ content in rats treated with intratracheal bleomycin compared to intratracheal normal saline). ${ }^{* *} P=0.0001^{\circ}$ ( $P$ was obtained comparing total lung TGF- $\beta$ content after intratracheal bleomycin and intramuscular MTP-A compared to intratracheal bleomycin alone). ${ }^{\sharp} P \leq 0.01$ ( $P$ obtained comparing TGF- $\beta$ content in CM of alveolar macrophages from rats treated with intratracheal bleomycin compared to intratracheal normal saline. $P$ is not significant. ( $P$ obtained comparing TGF- $\beta$ content in CM from alveolar macrophages from rats treated with bleomycin and intramuscular MTP-A compared to intratracheal bleomycin alone).

ence or absence of increasing concentrations of dexamethasone (Fig. 2). LPS stimulated alveolar macrophages to secrete both IL- 1 and TGF- $\beta$. The presence of dexamethasone completely inhibited the LPS-mediated secretion of IL-1 while the secretion of TGF- $\beta$ was not affected (Fig. 2). No independent effect attributable to dexamethasone at all the concentrations used

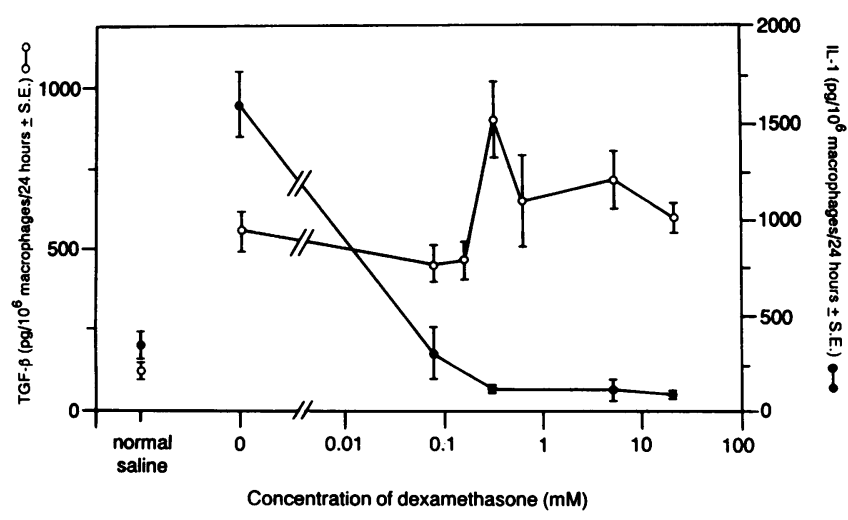

Figure 1. Effects of dexamethasone on secretion of TGF- $\beta(0-0)$ and

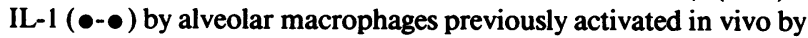
bleomycin-induced injury. $7 \mathrm{~d}$ after intratracheal bleomycin administration alveolar macrophages were obtained by bronchoalveolar lavage and cultured in the absence or presence of varying concentrations of dexamethasone. $24 \mathrm{~h}$ later, conditioned media was collected and the total TGF- $\beta$ content in the conditioned media was measured using the CCL-64 bioassay. An aliquot of the same conditioned media was used to measure the IL-1 content in a bioassay using NOB-1 cells in conjunction with a CTLL cell line. Each point is the mean of three to six experiments.

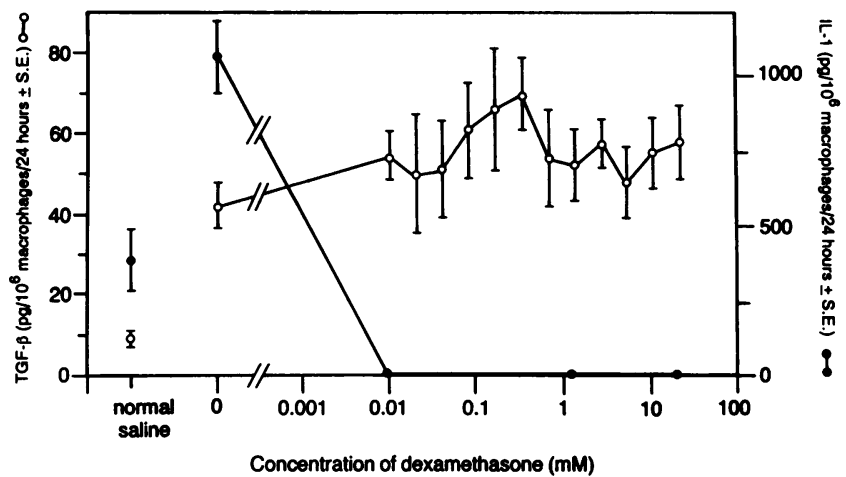

Figure 2. Effects of dexamethasone on secretion of TGF- $\beta(0-0)$ and

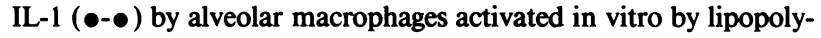
saccharide. Alveolar macrophages obtained by bronchoalveolar lavage from untreated rats were cultured for $24 \mathrm{~h}$ in the presence of $50 \mu \mathrm{g} / \mathrm{ml}$ of lipopolysaccharide and varying concentrations of dexamethasone. $24 \mathrm{~h}$ later, the conditioned media was collected, and the TGF- $\beta$ and IL-1 contents were measured as previously described. Each point is the mean of four experiments.

was seen in either the NOB-1/CTLL bioassay for IL-1 or the CCL-64 bioassay for TGF- $\beta$.

\section{Discussion}

We had previously reported (12) that total lung TGF- $\beta$ in bleomycin-induced pulmonary injury was maximally elevated $7 \mathrm{~d}$ after bleomycin administration. Using immunohistochemistry and antibodies to TGF- $\beta_{1}$, we demonstrated that $7 \mathrm{~d}$ after intratracheal bleomycin administration, TGF- $\beta_{1}$ was localized almost exclusively in alveolar macrophages.

In the present study, we confirmed that alveolar macrophages obtained $7 \mathrm{~d}$ after bleomycin administration not only produce TGF- $\beta_{1}$, but also secrete it in large quantities when explanted into tissue cultures (Table $\mathrm{I}$ ). With rare exception, TGF- $\beta$ is synthesized and secreted by cells as a biologically inactive propeptide called latent TGF- $\beta$ (L-TGF- $\beta$ ). Since TGF- $\beta$ and its receptors are ubiquitously expressed $(14,32)$, and since TGF- $\beta$ has numerous biological effects (14), the ability of a cell to activate L-TGF- $\beta$ upon secretion may be an important regulatory mechanism. In keeping with previous reports (28), we found that splenic macrophages secreted only L-TGF- $\beta$. However, alveolar macrophages obtained from rats after bleomycin administration, but not normal saline, secreted increased quantities of TGF- $\beta$ which was $\sim 80 \%$ in the active form (Table I). These findings indicate that bleomycin toxicity activates alveolar macrophages not only to increase TGF- $\beta$ secretion, but also activates the post-translational processing to increase the bioactive form of TGF- $\beta$. It is also of interest that bleomycin-induced toxicity that is limited to the lungs did not alter the secretion of TGF- $\beta$ by macrophages in other organ sites such as the spleen (Table I). This compartmentalization of TGF- $\beta_{1}$ secretion may be another mechanism of control of TGF- $\beta_{1}$ action in organ specific inflammation and fibrosis.

There are three isoforms of TGF- $\beta$ found in mammalian cells (14). The biological activities of these isoforms is indistinguishable in most in vitro assays (14). However, the expression of TGF- $\beta$ isoforms can vary both in vivo (33) and in vitro 
(34). For example, during murine palatogenesis, mRNA for TGF $-\beta_{3}$ is prominantly expressed in the early stages, while mRNA for TGF- $\beta_{1}$ is expressed by the same cells at a later stage (33). In addition, the in vitro regulation of TGF- $\beta$ isoforms can be modulated by retinoic acid, which increases TGF- $\beta_{2}$ expression while epidermal growth factor increases TGF- $\beta_{1}$ expression $(33,34)$. Little information exists on the mechanism of differential expression of TGF- $\beta$ isoforms. However, what is known is that each isoform is regulated by a different promoter. TGF- $\beta_{1}$ is regulated by a phorbol ester responsive AP-1 site (35), TGF $-\beta_{2}$ by a phorbol ester unresponsive AP-1 site, and cAMP-responsive elements (36), while TGF- $\beta_{3}$ is regulated by cAMP-responsive elements only (37). Using neutralizing antibodies to TGF $-\beta_{1}, \mathrm{TGF}-\beta_{2}$, and TGF- $\beta_{1-3}$, we were able to determine the relative quantities of each isoform of TGF- $\beta$ secreted by alveolar macrophages. Unstimulated alveolar macrophages secreted primarily TGF- $\beta_{1}$ with smaller quantities of TGF- $\beta_{2}$ and TGF $-\beta_{3}$ (Table II). However, activated alveolar macrophages obtained after bleomycin-induced pulmonary injury secreted increased quantities of TGF- $\beta_{1}$, while the quantities of TGF $-\beta_{2}$ and TGF- $\beta_{3}$ remained unchanged. The biological significance of this differential expression of TGF- $\beta$ isoforms by alveolar macrophages is presently unclear. However, what is evident in this study is that resting alveolar macrophages and alveolar macrophages during bleomycin-induced injury secrete different relative quantities of each isoform of TGF- $\beta$. Since alveolar macrophage-derived TGF- $\beta_{1}$ is the most prominant isoform detected during bleomycin-induced injury, it suggests that TGF- $\beta_{1}$ may have a primary role in the pathogenesis of the inflammatory and fibrotic responses seen in this model.

To confirm that alveolar macrophages were the primary source of TGF- $\beta$ after bleomycin injury, we used immunosuppressive doses of methylprednisolone to induce monocytopenia. In studies of wound closure, high doses of methylprednisolone induce systemic monocytopenia, including a marked decrease in wound monocytes and macrophages (29), as well as poor wound collagen synthesis and scar formation $(22,29)$. Administration of large doses of methylprednisolone before and concomitantly with bleomycin depleted alveolar macrophages to $<1 \%$ of controls (Table III) and total lung TGF- $\beta$ content was reduced to $1.2 \%$ of animals receiving bleomycin alone (Table IV). However, macrophages remaining in alveoli after treatment with bleomycin and methylprednisolone secreted active TGF- $\beta$ at the same rate as those macrophages obtained after bleomycin treatment only (Table IV). Thus, a decrease in activated macrophages in the alveolar compartment rather than any effects of corticosteroids on TGF- $\beta$ secretion by alveolar macrophages appeared to be responsible for the marked reduction in total lung TGF- $\beta$.

The total extractable lung TGF- $\beta$ represents all isoforms of TGF- $\beta$. This is of significance in the interpretation of the previous data because TGF- $\beta_{2}$ and TGF- $\beta_{3}$ in bleomycin induced pulmonary fibrosis are expressed in pulmonary epithelial cells and smooth muscle cells of bronchi and pulmonary vessels constitutively and at all times during the course of bleomycin induced injury (38). There is no evidence to indicate that epithelial and smooth muscle cell production of TGF- $\beta$ can be inhibited by corticosteroids. In other cell types, the evidence supports the induction of TGF- $\beta$ in the presence of corticosteroids (39). T lymphocytes activated by either purified phytohemagglutinin or phorbol-12-myristate-13-acetate in the pres- ence of corticosteroids have an increase in transcription and secretion of TGF- $\beta_{1}$ (39).

Corticosteroids inhibit many functions of activated macrophages including secretion of cytokines such as IL-1 (30) and TNF- $\alpha(40)$. In keeping with these reports, we demonstrated that dexamethasone inhibited IL-1 secretion by alveolar macrophages that were either previously stimulated by bleomycin injury or stimulated in vitro by LPS. However, corticosteroids had either little effect on macrophage secretion of TGF- $\beta$ or a slight induction of TGF- $\beta_{1}$ was observed at concentrations that suppressed IL-1 secretion. These findings indicate that corticosteroids differentially regulate cytokine production by activated alveolar macrophages. This may be clinically significant. Alveolar macrophages of patients with idiopathic pulmonary fibrosis, a lethal human fibrotic lung disease (12), contain TGF- $\beta_{1}$ and when cultured in vitro, these macrophages secrete large quantities of active TGF- $\beta_{1}$ into the medium (unpublished data). Corticosteroids are a standard therapy for human fibrotic lung diseases even though most patients with idiopathic pulmonary fibrosis do not respond to this treatment (12). If TGF- $\beta$ is as important to the pulmonary inflammatory and fibrotic responses as we have demonstrated $(12,41)$, then corticosteroid therapy administered in the advanced stages of the disease would likely not inhibit the TGF- $\beta$ production by alveolar macrophages. The relative resistance to corticosteroid therapy in pulmonary inflammatory and fibrotic responses seen in many human lung diseases may be caused by the corticosteroid insensitivity of TGF- $\beta$ production by alveolar macrophages. This suggests that only at the early inflammatory stages, when infiltration of macrophages is significant, that corticosteroid therapy is of benefit. However, at a later stage when alveolar macrophages are activated to secrete TGF- $\beta$, corticosteroids are ineffective.

In conclusion, we have demonstrated that during bleomycin-induced pulmonary inflammation, activated alveolar macrophages secreted large quantities of active TGF- $\beta_{1}$ while resting alveolar macrophages produced only small quantities of inactive TGF- $\beta_{1,2,3}$. Corticosteroids that are used as standard therapy for pulmonary fibrosis profoundly suppressed the influx of macrophages into the lungs during the early inflammatory response, but had little effect on the secretion of TGF- $\beta_{1}$ by activated alveolar macrophages.

\section{Acknowledgments}

We thank A. Warkentin and S. Snusher for typing the manuscript. We thank Dr. B. Tate for the statistical analysis of our data.

This work was supported by the Medical Research Council of Canada.

\section{References}

1. DePaso, W. J., and R. H. Winterbauer. 1991. Interstitial lung disease. Disease-a-Month 37:65-133.

2. Burkhardt, A., and H. Cottier. 1989. Alveolitis and collapse in the pathogenesis of pulmonary fibrosis. Virchows Arch. [B]. 58:1-13.

3. Chandler, D. B., D. M. Hyde, and S. N. Giri. 1983. Morphometric estimates of infiltrative cellular changes during the development of bleomycin-induced pulmonary fibrosis in hamsters. Am. J. Pathol. 112:170-177.

4. Haley, P. J., B. A. Muggenburg, D. N. Weissman, and D. E. Bice. 1991. Comparative morphology and morphometry of alveolar macrophages from six species. Am. J. Anat. 191:401-407.

5. Nathan, C. J. 1987. Secretory products of macrophages. J. Clin. Invest. 79:319-326. 
6. Hunninghake, G. W. 1987. Immunoregulatory functions of human alveolar macrophages. Am. Rev. Respir. Dis. 136:253-254.

7. Harmsen, A. G., B. A. Muggenberg, M. B. Snipes, and D. E. Bice. 1985. The role of macrophages in particle translocation from lungs to lymph nodes. Science (Wash. DC). 230:1277-1280.

8. Territo, M. C., and D. W. Golde. 1979. The function of human alveolar macrophages. J. Reticuloendothel. Soc. 25:111-120.

9. Jordana, M., C. Richards, L. B. Irving, and J. Gauldie. 1988. Spontaneous in vitro release of alveolar-macrophage cytokines after the intratracheal instillation of bleomycin in rats. Characterization and kinetic studies. Am. Rev. Respir. Dis. 137:1135-1140.

10. Martinet, Y., N. R. William, G. R. Grotendorst, G. R. Martin, and R. G. Crystal. 1987. Eagerated spontaneous release of platelet derived growth factor by alveolar macrophages from patients with idiopathic pulmonary fibrosis. New. Engl. J. Med. 317:202-209.

11. Bachwich, P. R., J. P. Lynch, J. Larrick, M. Spegloe, and S. L. Kunkel. 1986. Tumor necrosis factor stimulates interleukin-1 and prostaglandin E2 production in resting macrophages. Am. J. Pathol. 125:421-425.

12. Khalil, N., O. Bereznay, M. B. Sporn, and A. H. Greenberg. 1989. Macrophage production of transforming growth factor- $\beta$ and fibroblast collagen synthesis in chronic pulmonary inflammation. J. Exp. Med. 170:727-737.

13. Denholm, E. M. 1992. Continuous secretion of monocyte chemotactic factors and fibroblast growth factors by alveolar macrophages following a single exposure to bleomycin in vitro. Am. J. Path. 141:965-971.

14. Roberts, A. B., and M. B. Sporn. 1992. The transforming growth factorbetas. In Peptide Growth Factors and their Receptors. Handbook of Experimental Pharmacology. M. B. Sporn and A. B. Roberts, editors. Springer-Verlag New York Inc., New York. 95:419-472.

15. Roberts, A. B., M. B. Sporn, R. K. Assoian, J. M. Smith, N. S. Roche, L. M. Wakefield, U. I. Heine, L. A. Liotta, V. Falanga, J. H. Kehrl, and A. S Fauci. 1986. Transforming growth factor type-beta: rapid induction of fibrosis and angiogenesis in vivo and stimulation of collagen formation in vitro. Proc. Natl. Acad. Sci. USA. 83:4167-4171.

16. Assoian, R. K., B. E. Fleurdelys, H. C. Stevenson, P. J. Miller, D. K Madtes, E. W. Raines, R. Ross, and M. B. Sporn. 1987. Expression and secretion of type $\beta$ transforming growth factor by activated human macrophages. Proc. Natl. Acad. Sci. USA. 84:6020-6024.

17. Khalil, N., O. Bereznay, and A. H. Greenberg. 1990. Alveolar macrophages from bleomycin induced pulmonary inflammation synthesize and secrete transforming growth factor-beta (TGF- $\beta$ ). Am. Rev. Respir. Dis. 141:A138. (Abstr.)

18. Hayashi, K., G. Frangich, G. Wolfe, and K. R. Kenyon. 1989. Expression of transforming growth factor- $\beta$ in wound healing of vitamin A-deficient rat corneas. Invest. Opthamol. \& Visual Sci. 30:239-247.

19. Postlethwaite, A. E., J. Keski-Oja, H. L. Moses, and A. H. Kang. 1987. Stimulation of the chemotactic migration of human fibroblasts by transforming growth factor- $\beta$. J. Exp. Med. 165:251-256.

20. Ignotz, R. A., and J. Massague. 1986. Transforming growth factor-beta stimulates the expression of fibronectin and collagen and their incorporation into the extracellular matrix. J. Biol. Chem. 261:4337-4345.

21. Border, W. A., and E. Ruoslahti. 1992. Transforming growth factor- $\beta$ in disease: the dark side of tissue repair. J. Clin. Invest. 90:1-7.

22. Mustoe, T. A., G. F. Pierce, A. Thomason, P. Gramates, M. B. Sporn, and T. Deuel. 1987. Accelerated healing of incisional wounds in rats induced by transforming growth factor- $\beta$. Science (Wash. DC). 237:1333-1336.

23. Danielpour, D., K. Kyung-Young, L. L. Dart, S. Wantanabe, A. B. Roberts, and M. B. Sporn. 1989. Sandwich enzyme-linked immunosorbant assays (SELISAs) quantitate and distinguish two forms of transforming growth factorbeta (TGF- $\beta_{1}$ and TGF- $\beta_{2}$ ) in complex biological fluids. Growth Factors. 2:6171.

24. Holt, P. G. 1979. Alveolar macrophages. I. A simple technique for the preparation of high numbers of viable alveolar macrophages from small laboratory animals. J. Immunol. Methods. 27:189-198.

25. Horwitz, D. A., A. C. Allison, P. Ward, and N. Knight. 1977. Identification of human mononuclear leukocyte populations by esterase staining. Clin Exp. Immunol. 30:289-298.

26. Danielpour, D., L. L. Dart, K. C. Flanders, A. B. Roberts, and M. B. Sporn. 1989. Immunodetection and quantitation of the two forms of transforming growth factor-beta (TGF- $\beta_{1}$ and TGF- $\beta_{2}$ ) secreted by cells in culture. $J$. Cell. Physiol. 138:79-86.

27. Gearing, A. J., C. R. Bird, A. Bristow, S. Poole, and R. Thorpe. 1987. A simple sensitive bioassay for interleukin-1 which is unresponsive to $10^{3} \mathrm{U} / \mathrm{ml}$ of interleukin-2. J. Immunol. Methods. 99:7-11.

28. Wakefield, L. M., D. M. Smith, T. Masui, C. C. Harris, and M. B. Sporn 1987. Distribution and modulation of the cellular receptor for transforming growth factor- $\beta$. J. Cell Biol. 105:965-975.

29. Pierce, G. F., T. A. Mustoe, J. Lingelbach, V. R. Masakowski, P. Gramates, and T. F. Deuel. 1989. Transforming growth factor $\beta$ reverses the glucocorticoid-induced wound healing deficit in rats: possible regulation in macrophages by platelet-derived growth factor. Proc. Natl. Acad. Sci. USA. 86:22292233.

30. Snyder, D. S., and E. R. Unanue. 1982. Corticosteroids inhibit murine macrophage Ia expression and interleukin-1 production. J. Immunol. 129:18031805 .

31. Knudson, P. J., C. A. Dinarello, and T. B. Strom. 1987. Glucocorticoids inhibit transcriptional and post-transcriptional expression of interleukin-1 in U937 cells. J. Immunol. 139:4129-4134.

32. Segarini, P. R. 1991. TGF- $\beta$ receptors. In Clinical applications of TGF- $\beta$ G. R. Bock and J. Marsh, editors. Ciba Foundation Symposium 157, John Wiley and Sons, Ltd., Chichester, England. pp. 29-50.

33. Fitzpatrick, D. R., F. Denbez, P. Kondaiah, and R. J. Akhurst. 1990 Differential expression of TGF-beta isoforms in murine palatogenesis. Develop ment. 109:585-596.

34. Glick, A. B., K. C. Flanders, D. Danielpour, S. H. Yuspa, and M. B. Sporn. 1989. Retinoic acid induces transforming growth factor- $\beta_{2}$ in cultured keratinocytes and mouse epidermis. Cell Regul. 1:87-91.

35. Kim, S.-J., A. Glick, M. B. Sporn, and A. B. Roberts. 1989. Characterization of the promoter region of the human transforming growth factor- $\beta 1$ gene. $J$ Biol. Chem. 264:402-408.

36. Noma, T., A. B. Glick, and A. G. Geiser. 1991. Molecular cloning and characterization of the human TGF- $\beta_{2}$ gene promoter: cell-specific regulation and activation through the protein kinase A pathway. Growth Factors. 4:247256.

37. Lafyatis, R., R. Lechleider, S.-J. Kim, S. Jakowlew, A. B. Roberts, and M. B. Sporn. 1990. Structural and functional characterization of the transform ing growth factor- $\beta 3$ promoter: a cAMP responsive element regulates basal and induced transcription. J. Biol. Chem. 265:19128-19136.

38. O'Connor, R., N. Khalil, O. Bereznay, A. Kemp, and A. Greenberg. 1992 Increased expression of transforming growth factor beta (TGF- $\beta$ ) isoforms in bleomycin induced pulmonary fibrosis (BPF). Am. Rev. Respir. Dis. 145:A274 (Abstr.)

39. AyanlarBaterman, O., A. P. Ferraro, A. Diaz, and S. A. Jimenez. 1991. Regulation of transforming growth factor- $\beta 1$ gene expression by glucocorticoids in normal human T lymphocytes. J. Clin. Invest. 88:1574-1580.

40. Szefler, S. J., C. E. Norton, B. Ball, J. M. Gross, Y. Aida, and M. J. Pabst. 1989. IFN- $\gamma$ and LPS overcome glucocorticoid inhibition of priming for superoxide release in human monocytes. Evidence that secretion of IL-1 and tumor necrosis factor- $\alpha$ is not essential for monocyte priming. J. Immunol. 142:39853992.

41. Khalil, N., R. O'Connor, H. Unruh, P. Warren, A. Kemp, O. Bereznay, K Flanders, and A. H. Greenberg. 1990. Increased production and immunohistochemical localization of transforming growth factor-beta (TGF- $\beta$ ) in idiopathic pulmonary fibrosis. Am. J. Respir. Cell Mol. Biol. 5:155-162. 